\title{
Biocide tolerance in Salmonella from meats in Southern Spain
}

\author{
Antonio Marin Garrido ${ }^{1}, \mathrm{M}^{\mathrm{a}}$ Jose Grande Burgos ${ }^{2}, \mathrm{M}^{\mathrm{a}}$ Luisa Fernández Márquez ${ }^{2}$, \\ $\mathrm{M}^{\mathrm{a}}$ Carmen López Aguayo ${ }^{2}$, Rubén Pérez Pulido², Julia Toledo del Árbol ${ }^{2}$, \\ Antonio Gálvez ${ }^{2}$, Rosario Lucas López ${ }^{2}$ \\ ${ }^{1}$ Real Academia de Ciencias Veterinarias de Andalucía Oriental, Jaén, Spain. \\ ${ }^{2}$ Departamento de Ciencias de la Salud, Universidad de Jaén, Jaén, Spain.
}

Submitted: May 11, 2014; Approved: March 26, 2015.

\begin{abstract}
Salmonella serovars sampled from meat products in Southern Spain (Andalucía) during the period 2002-2007 were analyzed in this study. The serovars most frequently detected (in order) were Typhimurium, Enteritidis, Derby, Anatum and Rissen. Isolates $(n=43)$ were tested for sensitivity to biocides, including the quaternary ammonium compounds benzalkonium chloride (BC), cetrimide (CT) and hexadecylpyridinium chloride (HDP), and the bisphenols triclosan (TC) and hexachlorophene (CF). The minimum inhibitory concentration (MIC) for the quaternary ammonium compounds was in the range of 25 to $50 \mathrm{mg} / \mathrm{L}$ for most isolates, although a few isolates required much higher concentrations, up to $250 \mathrm{mg} / \mathrm{L}$. Bisphenols showed higher inhibitory activity, with a MIC of 2.5 to $25 \mathrm{mg} / \mathrm{L}$. A few isolates showed a "non-wildtype" MIC for TC of up to $250 \mathrm{mg} / \mathrm{L}$. These results indicate a low incidence of tolerance towards quaternary ammonium compounds and triclosan among Salmonella from meats and meat products.
\end{abstract}

Key words: Salmonella, biocides, serovars, meat, chorizo.

\section{Introduction}

Salmonella enterica is an important zoonotic foodborne pathogen and the causative agent of gastroenteritis and typhoid fever (Coburn et al., 2007). In 2012, salmonellosis was still the second most often reported zoonotic disease in humans in the EU accounting for 91,034 confirmed human cases, of which 4,181 occurred in Spain (EFSA-ECDC, 2014). The highest levels of non-compliance with Salmonella criteria generally occurred in foods of meat origin which were intended to be cooked before consumption (EFSA-ECDC, 2014). The common reservoir of Salmonella is the intestinal tract of a wide range of domestic and wild animals. For that reason, a variety of foodstuffs, including those of both animal and plant origin, can be a source of infection. Transmission often occurs when organisms are introduced in food preparation areas and are allowed to multiply in food, for example because of inadequate storage temperatures, inadequate cooking or cross contamination of ready-to-eat (RTE) foods.
Previously published reports have suggested that $\mathrm{Sal}$ monella can remain on surfaces and equipment used for handling and washing raw meat and that conventional cleaning and sanitation may fail to eradicate Salmonella from such surfaces (McKee et al., 2008; Arguello et al., 2012; Hernández et al., 2013). Biofilm formation is important for the persistence of Salmonella in the environment, allowing resistance to different stress factors including biocides (Steenackers et al., 2011). Biocidal compounds are widely used in the food industry for the disinfection of food containers, belts, production plants, to control microbial growth in food and drink, and to decontaminate animal carcasses (McDonnel and Russell, 1999; Cerf et al., 2010). Cationic agents such as benzalkonium chloride and chlorhexidine have been formulated as farm disinfectants (Boddie et al., 1997). Many different biocidal substances are also used for various purposes in the home, as building materials, consumer products or medical devices and on surfaces (SCENIHR, Scientific Committee on Emerging and Newly Identified Health Risks, 2009). Biocide tolerance in

Send correspondence to A. Gálvez. Área de Microbiología, Departamento de Ciencias de la Salud, Facultad de Ciencias Experimentales, Edif. B3, Universidad de Jaén, Campus Las Lagunillas s/n, 23071 Jaén, Spain. E-mail: agalvez@ujaen.es. 
bacteria is becoming a matter of concern because several resistance mechanisms can also accommodate other antimicrobials or are co-selected with antibiotic resistance (Ortega Morente et al., 2013). The increased use of biocides has raised concerns about a possible role in the selection for antibiotic resistant bacteria (Levy, 2002; Russell, 2001; Beier et al., 2004; Ortega Morente et al., 2013). Thus, acquisition of increased tolerance to biocides by zoonotic food-borne bacteria has important implications for public health. The purpose of the present study was to analyze the biocide tolerance of Salmonella strains from different types of meat products, including traditionally fermented meats such as chorizo. Initially, isolates of Salmonella detected in various meat sources in Andalucía (Southern Spain) during the period 2002-2007 were classified into serovars and then, a subset was selected for a bioide tolerance evaluation.

\section{Materials and Methods}

\section{Bacterial strains}

Isolates were obtained from a total of 112 meat samples that tested positive for Salmonella in accordance with the rules of EN/ISO 6579-2002 in official inspections carried out in the Andalucía region during the period 20022007. Isolates were serotyped by the "Laboratorio Nacional de Referencia para Salmonella y Shigella de España" (LNRSSE; Instituto de Salud Carlos III, Majadahonda, Madrid, Spain). Of these isolates, forty-three collected in Jaén (a province in the Andalucía region) were studied further for biocide resistance as described below. Isolates were routinely cultivated on brain heart infusion broth (BHI, Scharlab, Spain) at $37^{\circ} \mathrm{C}$, and stored in cultured broth supplemented with $20 \%$ glycerol at $-80{ }^{\circ} \mathrm{C}$.

\section{Determination of biocide tolerance}

Overnight cultures were inoculated $(1 \% \mathrm{vol} / \mathrm{vol})$ at approximately 1 x $10^{6} \quad \log _{10}$ colony forming units $(\mathrm{CFU}) / \mathrm{mL}$ in BHI broth supplemented with ten-fold serial dilutions of the following biocides: benzalkonium chloride (BC), cetrimide (CT), hexadecylpyridinium chloride
(HDPC), triclosan (TC) and hexachlorophene (CF). The $\mathrm{BC}$ commercial solution contained $50 \%(\mathrm{wt} / \mathrm{v})$ of the active compound. TC and CF were dissolved (10\% wt $/ \mathrm{v})$ in $96 \%$ ethanol. CT and HDPC were dissolved aseptically in sterile distilled water at final concentrations of $1.0 \%$. Biocides were purchased from Sigma-Aldrich (Madrid, Spain). Minimum inhibitory concentrations (MICs) were determined by the broth micro-dilution method in 96-well microplates after $24 \mathrm{~h}$ incubation at $37^{\circ} \mathrm{C}$. Growth and sterility controls were included for each isolate. Optical density (OD 595 $\mathrm{nm}$ ) was determined in an iMark Microplate Reader (BioRad, Madrid). Two independent determinations were conducted for each biocide, and in the case of discordant MIC values, a third repetition was carried out.

\section{Results and Discussion}

Between 2002 and 2007, a total of 112 meat samples in Andalucía were considered positive for Salmonella after identification and confirmatory tests for the corresponding 112 isolates by health inspection services (Table 1). The meat products most frequently confirmed as contaminated with Salmonella in Andalucía were derived from pork, especially "chorizo", a traditional type of sausage that is slightly fermented and ripened for a variable time period and often consumed without cooking. It has been reported that Enterobacteriaceae (including Salmonella) are generally either stable or increase slightly at the beginning of the ripening of chorizo, and then decrease during the late ripening period (Domínguez et al., 1989; Castaño et al., 2002). Previous studies have shown the presence of Salmonella in Mexican chorizo (Kuri et al., 1995; Escartín et al., 1999), and an outbreak involving 294 people (of which 73 were confirmed of salmonellosis and 221 were classified as probable cases), associated with the consumption of chorizo in restaurants in Nevada, USA (Nguyen, 2013), was reported in 2013. While poultry products have been traditionally considered as the principal source of Salmonella contamination, pork products are also very significant. According to EFSA-ECDC 2012 report (EFSA-ECDC, 2014), the highest levels of positive samples at the slaughterhouse were found in Belgium (10.8\%) and Spain (7.8\%).

Table 1 - Sources of the 112 confirmed Salmonella isolates from meats and meat products in Andalucía for the period $2002-2007$.

\begin{tabular}{|c|c|c|c|}
\hline Meat samples & Percentage of isolates $(\%)$ & Meat samples & Percentage of isolates $(\%)$ \\
\hline Fresh chorizo & 29.46 & Fresh bovine meat & 1.79 \\
\hline Ripened chorizo & 31.25 & Hamburger meat & 3.57 \\
\hline Extra quality chorizo & 1.79 & Fresh turkey breast & 1.79 \\
\hline Fresh pork meat & 9.82 & Sliced chicken meat & 1.79 \\
\hline Minced pork meat & 2.68 & Roasted chicken & 1.79 \\
\hline Deboned pork meat & 1.79 & Fresh poultry sausages & 4.46 \\
\hline Meat sausages & 1.79 & Others & 1.79 \\
\hline Stuffed meat & 4.46 & & \\
\hline
\end{tabular}


The 112 confirmed Salmonella isolates belonged mainly to the following serovars (in order): Typhimurium, Enteritidis, Derby, Anatum and Rissen (Table 2). These results agree with the data from EFSA reports that identify $S$. Enteritidis and $S$. Typhimurium as the serovars most frequently associated with human salmonellosis in the EU as well as in the US (EFSA-ECDC, 2014; Centers for Disease Control, 2006). Human $S$. Enteritidis cases are most commonly associated with the consumption of contaminated eggs and poultry, while $S$. Typhimurium cases are mostly associated with the consumption of contaminated pork or beef (EFSA-ECDC, 2014). The subset of 43 isolates from the Jaén province was obtained both during routine inspection and also during a specific control program for all meat vendors in the province, as well as from meat products implicated in salmonellosis. Among these, the Typhimurium serovar was still the most prevalent (Table 2), but the Anatum and Derby serovars were also important, and the Enteritidis serovar was much less prevalent and had the same incidence as the Rissen, Brandenburg or Ohio serovars. According to previous studies, $S$. Typhimurium and $S$. Derby are two of the most frequent $S$. enterica serovars found in pigs across the EU (EFSA, 2010; Matiasovic et al., 2014). While $S$. Typhimurium can colonize many animal species, $S$. Derby is adapted to pigs (Hoelzer, 2011) and contaminated pork is a common source of human $S$. Derby in Europe (Hauser et al., 2011; Kerouanton et al., 2013). The Rissen serovar is also frequently associated with pigs (Vico et al., 2011). Salmonella Anatum is most frequently associated with red meat (Fegan et al., 2005; Humphrey and Jørgensen, 2006), but it can also be associated with poultry (Angkititrakul et al., 2005) and pigs (Hoelzer et al., 2011).

In a recent study (Hernández et al., 2013), up to fourteen different serotypes of Salmonella were isolated from a free-range pig processing plant (tracking in trucks, lairage, slaughter line and quartering). It was concluded that the processing plant might represent a high risk for the contamination of pork from free-range pigs both prior to and after slaughter, requiring proper cleaning and disinfection operations (Hernández et al., 2013). Effective hygiene control measures coupled with the use of appropriate disinfection regimens are important tools for the control of Salmonella
Table 2 - Relative abundance of serovars among the 112 Salmonella confirmed isolates from meat samples in Andalucía during the period 20022007 , including the 43 isolates from the province of Jaen.

\begin{tabular}{lcc}
\hline Serovar & Andalucía (\%) & Jaén (\%) \\
\hline Typhimurium & 34.82 & 41.86 \\
Anatum & 12.50 & 16.28 \\
Enteritidis & 17.86 & 4.65 \\
Derby & 13.39 & 11.63 \\
Rissen & 4.46 & 4.65 \\
Brandenburg & 3.57 & \\
Bredeney & 1.79 & \\
Agona & 0.89 & \\
Ohio & 4.65 & \\
Others* & 10.71 & 11.63 \\
\hline
\end{tabular}

*Other serovars for Andalucía include monophasic variant, Gold Coast, London, Nottingham, Ohio, Panama and Senftenberg, as well as London, Give, Nottingham, Panama and Senftenberg for Jaén province.

in food production and processing environments. Because biocides are widely used for disinfection, we wanted to determine the biocide tolerance of Salmonella in the available isolates from the province of Jaen. Among the quaternary ammonium compounds tested, benzalkonium chloride inhibited most isolates $(86.047 \%)$ at $50 \mathrm{mg} / \mathrm{L}$ and only one isolate $(2.33 \%)$ required a much higher concentration of $250 \mathrm{mg} / \mathrm{L}$ for inhibition (Table 3). Cetrimide showed an activity similar to that of benzalkonium chloride, although there were more isolates requiring a biocide concentration higher than $50 \mathrm{mg} / \mathrm{L}$. Hexadecylpyridinium chloride also showed the highest activity at $50 \mathrm{mg} / \mathrm{L}$, inhibiting $55.82 \%$ of isolates at this concentration. The bisphenol triclosan was the most active of all the biocides tested, inhibiting $79.07 \%$ of the isolates at $5 \mathrm{mg} / \mathrm{L}$. However, 9 isolates required higher concentrations of this biocide for inhibition. One isolate had a MIC of $250 \mathrm{mg} / \mathrm{L}$. Another bisphenol, hexachlorophene, was less effective than triclosan at $2.5 \mathrm{mg} / \mathrm{L}$, but none of the isolates tested required a biocide concentration higher than $25 \mathrm{mg} / \mathrm{L}$ for inhibition. Altogether, the results obtained show that most investigated isolates of Salmonella can be inhibited by relatively low biocide concentrations. For most of the biocides tested,

Table 3 - Minimum inhibitory concentrations of biocides for Salmonella strains from meats. The percentages (\%) of isolates inhibited at each biocide concentration are shown.

\begin{tabular}{|c|c|c|c|c|c|}
\hline \multirow[b]{2}{*}{ Biocide } & \multicolumn{5}{|c|}{ Minimum inhibitory concentrations of biocide (mg/L) } \\
\hline & 2.5 & 25 & 50 & 100 & 250 \\
\hline Benzalkonium chloride & 2.33 & 9.30 & 86.04 & & 2.33 \\
\hline Cetrimide & & 4.65 & 88.37 & 4.65 & 2.33 \\
\hline Hexadecylpyridinium chloride & & 37.20 & 55.82 & 6.98 & \\
\hline Triclosan & 79.06 & 9.30 & 6.98 & 2.33 & 2.33 \\
\hline Hexachlorophene & 51.16 & 48.84 & & & \\
\hline
\end{tabular}


there was always a concentration at which most isolates were sensitive. That concentration represents the limit of biocide tolerance for the wildtype population and is also known as the epidemiological cutoff value (ECOFF). In contrast, isolates with a higher ("non-wildtype") MIC should be considered biocide tolerant. Furthermore, one isolate had a high MIC for three different biocides (including all of the quaternary ammonium compounds and triclosan), and two others had a MIC of $100 \mathrm{mg} / \mathrm{L}$ for both cetrimide and hexadecylpyridinium chloride. Isolates with a non-wildtype MIC as well as those with tolerance to multiple biocides should be further investigated regarding genetic determinants for biocide tolerance.

Benzalkonium chloride is widely used for sanitizing the surfaces of utensils and instruments in the food industry (Ueda and Kuwabara, 2007; SCENIHR, 2009). Hexadecylpyridinium chloride (cetylpyridinium chloride) was approved in 2004 by the US FDA for decontaminating raw poultry at a working concentration not exceeding $0.8 \%$ by weight (Food and Drug Administration, 2004). Another common biocide is triclosan, which is now incorporated in a wide range of products such as dishcloths, food boxes, toothbrushes, washing-up liquid and hand-washing gels, plastics, chopping boards, chopsticks, pizza cutters, food storage containers, garbage bags, and kitty litter, among others. Hexachlorophene is often used in soaps and also as a topical anti-bacterial agent (Yazdankhah et al., 2006; SCENIHR, 2009). In conclusion, results from this study indicate that a low percentage of the Salmonella isolates investigated can tolerate biocides belonging to the groups of quaternary ammonium compounds (benzalkonium chloride, cetrimide and hexadecylpyridinium chloride) and bisphenols (triclosan). Therefore, it seems likely that exposure to these biocides could result in the selection of salmonellae able to tolerate higher biocide concentrations. Accordingly, a possible contribution of biocide tolerance to the persistence of Salmonella in the food chain should be further investigated. There is a concern that biocide tolerance might co-select for antibiotic resistance determinants in the food chain (reviewed by Ortega Morente et al., 2013). Therefore, further studies should be carried out on the antibiotic resistances of Salmonella isolates that have shown a higher tolerance to biocides.

\section{Acknowledgments}

This work was supported by research project P08AGR-4295 (CICE, FEDER) and University of Jaén Research Funding Plan (Ref. UJA2013/10/06).

\section{References}

Angkititrakul S, Chomvarin C, Chaita T et al. (2005) Epidemiology of antimicrobial resistance in Salmonella isolated from pork chicken meat and humans in Thailand. Southeast Asian J Trop Med Public Health 36:1510-1515.
Arguello H, Carvajal A, Collazos JA et al. (2012) Prevalence and serovars of Salmonella enterica on pig carcasses slaughtered pigs and the environment of four Spanish slaughterhouses. Food Res Int 45:905-912.

Beier RC, Bishoff KM, Poole TL (2004) Disinfectants (biocides) used in animal production: antimicrobial resistance considerations. In Beier RC, Pillani SD, Phillips TD et al. (ed). Preharvest and postharvest food safety: contemporary issues and future directions. Blackwell Publishing Professional, Ame, p 227-238.

Boddie RL, Nickerson SC, Adkinson RW (1997) Efficacies of teat germicides containing $05 \%$ chlorhexidine and $1 \%$ iodine during experimental challenge with Staphylococcus aureus and Streptococcus agalactiae. J Dairy Sci 80:28092814.

Castaño A, Garcia Fontán MC, Fresno JM et al. (2002) Survival of Enterobacteriaceae during processing of Chorizo de cebolla, a Spanish fermented sausage. Food Control 13:107-115.

Centers for Disease Control and Prevention (2006) Multistate outbreak of Salmonella Typhimurium infections associated with eating ground beef - United States, 2004. MMWR Morb Mortal Wkly Rep 50:180-182.

Cerf O, Carpentier B, Sanders P (2010) Tests for determining in-use concentrations of antibiotics and disinfectants are based on entirely different concepts: "Resistance" has different meanings. Int J Food Microbiol 136:247-254.

Coburn B, Grassl GA, Finlay BB (2007) Salmonella the host and disease: a brief review. Immunol Cell Biol 85:112-118.

Domínguez MC, Gutérrez LM, López A et al. (1989) Evolución de los principales grupos de microorganismos durante la maduración del chorizo de León. Alimentaria 26:11-15.

EFSA (2010) Quantitative microbiological risk assessment on Salmonella in slaughter and breeder pigs: Final report VLA/RIVM/Food-DTU. (Available online: http://www efsa europa eu/en/scdocs/doc/46e pdf. Accessed May 7, 2014)

EFSA-ECDC (2014) The European Union Summary Report on Trends and Sources of Zoonoses Zoonotic Agents and Food-borne Outbreaks in 2012. EFSA J 12:3547.

Escartín EF, Castillo A, Hinojosa-Puga A et al. (1999) Prevalence of Salmonella in chorizo and its survival under different storage temperatures. Food Microbiol 16:479-486.

Fegan N, Vanderlinde P, Higgs G et al. (2005) A study of the prevalence and enumeration of Salmonella enterica in cattle and on carcasses during processing. J Food Prot 68:11471153.

Food and Drug Administration (2004) Department of Health and Human Services 21 CFR Part 173 375. Federal Register/Vol 69 No 64/Friday April 2 2004/Rules and Regulations.

Hauser E, Hebner F, Tietze E et al. (2011) Diversity of Salmonella enterica serovar Derby isolated from pig pork and humans in Germany. Int J Food Microbiol 151:141-149.

Hernández M, Gómez-Laguna J, Luque I et al. (2013) Salmonella prevalence and characterization in a free-range pig processing plant: Tracking in trucks lairage slaughter line and quartering. Int J Food Microbiol 162:48-54.

Hoelzer K, Moreno Switt AI, Wiedmann M (2011) Animal contact as a source of human non-typhoidal salmonellosis. Vet Res 42:34. 
Humphrey T, Jørgensen F (2006) Pathogens on meat and infection in animals - Establishing a relationship using Campylobacter and Salmonella as examples. Meat Sci 74:89-97.

Kerouanton A, Rose V, Weill FX et al. (2013) Genetic diversity and antimicrobial resistance profiles of Salmonella enterica serotype Derby isolated from pigs pork and humans in France. Foodborne Pathog Dis 10:977-984.

Kuri V, Madden RH, Collins MA (1995) Hygienic quality of raw pork and chorizo (raw pork sausage) on retail sale in Mexico City. J Food Prot 59:141-145.

Levy SB (2002) Active efflux, a common mechanism for biocide and antibiotic resistance. J Appl Microbiol 92:65S-71S.

Matiasovic J, Stepanova H, Kudlackova H et al. (2014) Immune response of pigs to Salmonella enterica serovar Derby and Typhimurium infections. Vet Microbiol 170:284-290.

McDonnel G, Russell AD (1999) Antiseptics and disinfectants: activity action and resistance. Clin Microbiol Rev 12:147179.

McKee S, Townsend J, Bilgili S (2008) Use of a scald additive to reduce levels of Salmonella Typhimurium during poultry processing. Poultry Sci 87:1672-1677.

Nguyen L (2013) Salmonella Gastroenteritis Outbreak Among Patrons of Firefly on Paradise Restaurant - Las Vegas Nevada Southern Nevada Health District Interim Report 3 (Available online: http://www southernnevadahealthdistrict org/download/stats-reports/firefly-interim-report-052213 pdf. Accessed on May 7, 2014).

Ortega-Morente E, Fernández-Fuentes MA, Grande-Burgos MJ et al. (2013) Biocide tolerance in bacteria. Int J Food Microbiol 162:13-25.

Russell AD (2001) Mechanisms of bacterial insusceptibility to biocides. Am J Infect Contr 29:259-261.

SCENIHR Scientific Committee on Emerging and Newly Identified Health Risks (2009) -Assessment of the Antibiotic Resistance Effects of Biocides January 2009 24-25 (Available online: http://ec europa eu/health/archive/ph_risk/committees/04_scenihr/docs/scenihr_o_021 pdf. Accessed on May 7, 2014) .

Steenackers H, Hermans K, Vanderleyden J et al. (2011) Salmonella biofilms: an overview on occurrence, structure, regulation and eradication. Food Res Int 45:502-531.

Vico JP, Rol I, Garrido V et al. (2011) Salmonellosis in finishing pigs in Spain: prevalence antimicrobial agent susceptibilities and risk factor analysis. J Food Prot 74:1070-1078.

Ueda S, Kuwabara Y (2007) Susceptibility of biofilm Escherichia coli Salmonella Enteritidis and Staphylococcus aureus to detergents and sanitizers. Biocontrol Sci 12:149-153.

Yazdankhah SP, Scheie AA, Høiby EA et al. (2006) Triclosan and antimicrobial resistance in bacteria: an overview. Microb Drug Resist 12:83-90.

Associate Editor: Elaine Cristina Pereira De Martinis

All the content of the journal, except where otherwise noted, is licensed under a Creative Commons License CC BY-NC. 